\title{
An ensonified bubble curtain blocks 4 species of invasive carp in a laboratory flume but also deters other fish, while sound alone is less effective overall and does not target carp
}

\section{Jane Rose Feely}

University of Minnesota Twin Cities: University of Minnesota

Peter Sorensen ( $\square$ soren003@umn.edu )

University of Minnesota https://orcid.org/0000-0003-0321-1279

\section{Research Article}

Keywords: Bioacoustic Fish Fence, BAFF, carp, native fish, grass carp, silver carp

Posted Date: September 20th, 2021

DOl: https://doi.org/10.21203/rs.3.rs-799849/v1

License: (c) (1) This work is licensed under a Creative Commons Attribution 4.0 International License. Read Full License 


\section{An ensonified bubble curtain blocks 4 species of invasive carp in a laboratory flume but}

2 also deters other fish, while sound alone is less effective overall and does not target carp

5 Jane R. Feely and Peter W. Sorensen*

6 Department of Fisheries, Wildlife and Conservation Biology

7 University of Minnesota

82003 Upper Buford Circle

9 St. Paul, MN 55108, USA

11 Abstract Four species of invasive carp from Asia are advancing up the Mississippi River

12 through its locks and dams and threatening to damage to its ecosystems. It has been

13 hypothesized that sensory stimuli could be projected into locks to block the movement of these

14 carp. Sound has garnered attention because carp are hearing specialists, so they might be

15 targetable. A recent study demonstrated that when a broadband cyclic sound was projected into

16 an air curtain to create an ensonified bubble curtain (EBC), it was especially effective at blocking

17 bighead and common carp and less effective at blocking a native species that lacked hearing

18 specializations, while sound alone was generally less effective. However, whether an EBC

19 might be similarly and uniquely effective at blocking all species of carp, and what its effects

20 might be on other fishes in general, has not yet been addressed. To answer these questions, this

21 study examined the responses of 10 species of fishes including 4 carps, 2 native hearing

22 specialists, and 4 native non-specialists in a darkened laboratory flume while either a cyclic

23 sound was played on its own or projected into an air curtain. The EBC blocked all 4 carps 92-

$2497 \%$ of the time without habituation, but 5 native fish were also partially blocked. In contrast,

25 sound alone only blocked 2 carps and affected the other fishes in ways not related to their

26 hearing abilities. An EBC appears well suited to blocking carp invasions, especially if native

27 fish movement is a secondary concern.

Keywords Bioacoustic Fish Fence; BAFF; carp; native fish; grass carp; silver carp 
In the 1970's, four species of carp from Asia were introduced into sewage and aquaculture ponds in the southern United States from which they escaped into the Mississippi River (Kolar et al. 2007; Chapman and Hoff 2011; Reeves 2019). These species joined the common carp (Cyprinus carpio) which had been introduced from Europe a century before and now dominates many lake and river ecosystems worldwide (Sorensen and Bajer 2011). The "Asian" carps are currently breeding and moving away from their site of introduction, threatening ecosystems in the upper reaches and tributaries of the Mississippi River as well as the Laurentian Great Lakes (ACRCC 2021). In most regions, the silver carp (Hypophthalmichthys molitrix) is of greatest concern

42 because it is a highly efficient planktivore (Dong and Li 1994; Claus and Sorensen 2019) and jumps when startled (Stell et al. 2020). Its congener, the bighead carp (H. nobilis), is also

44 considered a serious threat because it often grows to a large size ( $40 \mathrm{~kg}$; Kolar et al. 2007) and

45 hybridizes with silver carp (Lamer et al. 2010). In addition to the bigheaded carps (i.e. the silver 46 and bighead carps), concerns are growing about the grass carp (Ctenopharyngodon idella), which

47 feeds on plants and is now breeding in some tributaries of Lake Erie (Cudmore and Mandrak

48 2004; Embke et al. 2016). Further, in the southern United States, the black carp

49 (Mylopharyngodon piceus) threatens its mollusks (Nico and Jelks 2011). Finally, the common carp remains a concern because although well established, management efforts continue to

51 remove it from waterbodies which managers do not wish them to re-invade (Sorensen and Bajer

52 2011). All of these carps exhibit migratory behaviors (deGrandcahamp et al. 2008; Harris et al.

53 2021; Banet et al. 2021) which, in the Mississippi River and its tributaries, results in their

54 swimming through locks and dams to invade upstream habitats. Accordingly, locks and dams

55 are being considered as pinch-points in rivers to block invasive carps by performing various 56 actions including adding carp deterrent systems (ACRCC 2021; Zielinski and Sorensen 2021).

57 An especially promising option to stop the invasion of carp is to place deterrent systems

58 in the navigation locks of locks and dams, especially locks and dams with spillway gates that 59 rarely open and are thus not routinely passable so fish must pass through their locks (Zielinski et 60 al. 2018; Zielinski and Sorensen 2021). Several types of deterrent systems are being considered 61 for use in locks (Noatch and Suski 2012), but those which use nonphysical, or sensory stimuli, 62 are favored. This is because nonphysical systems are relatively simpler and less expensive to 
63 install and run, do not pose a hazard to human health, and have the potential to target particular

64 species because different fish species have different sensory capabilities (Fay and Tavolga 2012).

65 Sound is of special interest because it is relatively easy to project and carp, like other

66 ostariophysan fishes, have an exceptional sense of hearing because they possess a type of hearing

67 specialization known as Weberian ossicles (Popper and Carlson 1998). A Weberian apparatus

68 can extend the hearing range of fish up to $\sim 1000 \mathrm{hz}$ and increase their sensitivity by several fold

69 (Popper and Carlson 1998; Putland and Mensinger 2019). While the effects of various sounds

70 have been tested on about a dozen species of fish and found to have promise, a wide range of

71 deterrence efficiencies have also been described; however, these tests have used a variety of

72 testing apparatuses, experimental protocols, and sound signals, so conclusions about their true

73 potential remain elusive (Zielinski and Sorensen 2017; Murchy et al. 2016; Putland and

74 Mensinger 2019). Nevertheless, habituation, the phenomenon in which animals learn to ignore

75 biologically-irrelevant stimuli and become less responsive to them with repeated exposure, has

76 emerged as a concern (Zielinski and Sorensen 2017; Dennis and Sorensen 2020a). In sum, it

77 remains an open question whether fish with hearing specializations including carps are more

78 deterred by sound than species that lack specializations and why.

Because of the variability and often low level of responsiveness of fish to sound, studies

81 take advantage of all of their properties. One of the best studied of these are ensonified bubble

82 curtains (EBCs), a type of stimulus in which sound is projected into an air bubble stream (i.e. air

83 curtain) to focus and enhance sound fields while often causing its bubbles to resonate (Brevik

84 and Kristiansen 2002; Leighton 2012; Dennis et al. 2019). In addition, bubble curtains can be

85 aversive in their own right because they have their own acoustic, physical, and visual properties

86 which can be felt and heard by fish acoustico-lateralis system as well as visualized (Zielinski et

87 al. 2014; Zielinski and Sorensen 2016). A commercial version of an EBC is available and

88 known as a bioacoustic fish fence (BAFF) (https://www.fgs.world) and has been tested a few

89 times with some success. Welton et al. (2002) found that young, downstream-migrating Atlantic

90 salmon (Salmo salar) were deterred by a BAFF by 66-79\% in a small stream with the highest

91 efficiencies being observed at night. A similar finding without a day-night effect was noted for

92 downstream-migrating Chinook salmon smolts (Oncorhynchus tshawytscha) in a large river,

93 although this BAFF was illuminated and no day-night effect was noted (Perry et al. 2014). In a 
raceway test, Taylor et al. (2005) found that bighead carp were repelled up to $95 \%$ of the time by

95 a BAFF but no other fish was tested, nor was sound alone. Later, in a field test, a variety of

96 fishes (including some carps) were captured and transplanted downstream of an illuminated

97 BAFF and it was seen to reduce the upstream recapture of many species, including silver carp,

98 suggesting this system can work in the field, but not how well, or why (Ruebush et al. 2012).

99 Finally, in a laboratory test of an EBC, we found that common carp and bighead carp were

100 nearly completely blocked by an EBC in a darkened lab flume (blockage efficiencies of $97 \%$ and

$10199 \%$ respectively) while largemouth bass (Micropterus salmoides), which lack hearing

102 specializations, were blocked to a lesser (86\%) extent (Dennis et al. 2019). We also found that

103 an EBC worked more effectively than sound or air alone and that a cyclic broadband sound was

104 especially effective. In sum, while these studies suggest that EBCs have promise to block carp

105 and might even be able to target them, this type of stimulus has only been tested on a few species

106 including two carps so conclusions about its broad applicability for field implementation cannot

107 be drawn.

108 The overarching goal of this study was to determine if EBCs are a better option to control

109 invasive carps than sound alone and if either option can target carps without significantly

110 affecting native fishes. We asked two questions. First, does a cyclic broadband sound

111 effectively block all four species of carp without affecting other fishes including native hearing

112 specialists? Second, does this sound block carps more effectively than sound alone, and if so,

113 what effects might it have on native fishes, including hearing specialists? To answer these

114 questions, we tested the responses of 4 species of invasive carp, as well as 2 native fish species

115 with hearing specializations and 4 without hearing specializations, to sound alone and an EBC in

116 the darkened laboratory flume with protocols we have used previously (Dennis et al. 2019;

117 Dennis and Sorensen 2020b).

Materials and methods

121

122 Experimental Design 
124 Experiments proceed in a stepwise fashion, following established approaches (Dennis et al 2019;

125 Dennis and Sorensen 2020b). First, we selected native species of interest as well as species of 126 invasive carp that we could obtain from local hatcheries (see below). Second, we brought these

127 fish into the laboratory where they were held in large aquaria (see below). Third, these fish were 128 then tested following established protocols (Dennis et al. 2019) in a 8-m darkened laboratory 129 flume as groups of 10 to one of three stimuli: 1) no stimulus ("no-treatment control" to determine 130 their basal level of activity); 2) a cyclic sound (the same sound tested by Dennis et al. 2019; see 131 below); or 3) this cyclic sound coupled with air to create an EBC (also the same as Dennis et al. 132 2019; see below). After a 1-h pre-test/acclimation period, these groups of fish were tested 8 133 times (each testing period was considered a trial), each of which had two sets of 6-min periods, a 134 6-min pre-test with no stimulus, followed by a 6-min test period with a stimulus. Trials were 135 separated by a 10-min period with no stimulus to permit recovery. The flume was designed so a 136 stimulus could be played on either side with side being selected at random by coin-toss for each 137 experimental trial. Each experiment took a total of $238 \mathrm{~min}$. Fish position was recorded during 138 the pre-test and test-periods (test number) using overhead cameras (confirming crossing if/as 139 necessary using underwater cameras), then analyzed by quantifying the number of times fish 140 crossed the midline where the deterrent system was located (i.e., passage rate) for each pre-test 141 or test period. Because we had a disease problem with our bighead carp, we used the data 142 collected by Dennis et al. (2019) for this species although it was re-analyzed as our analysis 143 differed slightly. Fish were only tested once so all fish were naive and we could address 144 habituation with clarity.

149 In addition to the four species of carp that we could obtain from local hatcheries, we selected a 150 variety of 6 native fishes based on availability, taxonomic variety, ecology, and whether or not 151 they had hearing specializations (Table 1). Fish were sexually immature and ranged in size from 152 about 90-200 $\mathrm{mm}$ in total length (TL). Channel catfish (Ictalurus punctatus) and lake sturgeon 153 (Ascipneser fulvescens) were obtained from the Genoa National Fish Hatchery (Genoa, WI, 154 USA) while bluegill sunfish, (Lepomis macrochirus), largemouth bass, golden shiners 
(Notemigonus crysoleucas), common carp, rainbow trout (Oncorhynchus mykiss), grass carp,

156 bighead carp, and silver carp were obtained from Osage Catfisheries (Osage Beach, MO, USA).

157 All fish were shipped to the University of Minnesota and placed into inflow-through 1000L

158 circular tanks prior to testing for at least 3 months supplied with well water on a 16:8 L:D

159 photoperiod. Bluegill sunfish, channel catfish, largemouth bass, golden shiners, common carp, 160 rainbow trout, and grass carp were fed $2.5 \mathrm{~mm}$ floating pellets (Skretting USA, Tooele, UT, 161 USA). Silver carp and bighead carp were fed a mixture of Spirulina and Chlorella algae (Claus 162 and Sorensen 2017; Nuts.com, NJ, USA). Lake sturgeon were fed brine shrimp (Hikari, Japan). 163 Procedures were approved by the University of Minnesota Institutional Animal Care and Use 164 Committee (Protocol: 1712-35381A) and all necessary federal and state permits were obtained.

Experiments were performed in the same custom-built indoor elliptical flume ( $8 \mathrm{~m}$ long x $1 \mathrm{~m}$ wide channel, $1.0 \mathrm{~m}$ wall height) employed by Dennis et al. (2019) who provides a detailed

171 description so only an overview is provided here for context. Briefly, the flume was constructed

172 of fiberglass and its floor and walls (inside and out) lined with concrete pavers with foam pads to 173 reduce sound reverberation. Sound/air sources which were positioned on its bottom at the mid-

174 line of each of its long sides. The flume was located in a dark and quiet room and illuminated 175 with 6 overhead infrared illumination systems ( $840 \mathrm{~nm},<1-l u x$; VT-IR1, Vitek, Valencia, CA). 176 Low-light cameras were also positioned overhead so fish position could be observed at a remote 177 location. Several underwater cameras were also placed in the flume so that crossings through the 178 bubble curtain could be confirmed when needed. Well water $\left(18^{\circ} \mathrm{C}\right)$ was supplied to the flume 179 until 1-h before the experiments started, when it was turned off except for the bighead carp trials 180 for which a slow flow was maintained as we found they stopped swimming in stagnant water. 181 Water depth was maintained at $0.3 \mathrm{~m}$. 
We used the same speakers, sound, and EBC set-up as that employed by Dennis et al (2019) who provides detailed descriptions of all three so only an overview is provided here for context. Briefly, the sound system was comprised of two sets of two speakers (FGS MkII 15-100; Fish Guidance System Ltd.; Southampton, UK), which were positioned equidistant from each other at the center of each of the long sides of the flume alongside two fine porous pipes (AD100T; Pentair AES; Apopka, FL). For EBC experiments the porous pipes were supplied with air at a rate of $1.2 \mathrm{~L} \mathrm{~s}^{-1}$ to create a fine bubble stream via blowers located in another room while sound settings were left as is. Our test sound contained frequencies between 20-2000 hz which cycled (Sound 7, Fish Guidance Systems) and was played at a volume to create a sound field of 150$160 \mathrm{db}$ at $1000 \mathrm{hz}($ ref $1 \mu \mathrm{Pa})$ at the source (Fig. 1; see Dennis et al. 2019 for detail). Sound pressure and particle acceleration levels for both the sound and EBC were mapped using a C15 hydrophone (Cetacean Research, Seattle, WA) as well as an accelerometer (TASCAM US12mkII; TEAC, Montebello, CA). Dennis et al. (2019) provide initial descriptions of this sound and the EBC including spectrograms and elaborate here by showing sound maps for sound pressure (SPL $\mathrm{RMS}$ ) at three selected frequencies within the carps' hearing range: 500-600hz, 1000-1100hz, and 1500-1600hz. These maps appear to show much sharper sound pressure gradients near the stimulus for the EBC than sound alone, especially for the higher frequencies,

205 but that maximum sound pressures were similar (Fig. 1).

Statistical Analysis

Similar to Dennis et al. (2019) and Dennis and Sorensen (2020a), we used a step-wise approach

211 to analyze our results which was based on generalized linear mixed models (GLMM). Ten

212 models were used in total, one for each species. This approach used custom-built matrices to

213 facilitate comparisons between species and their responses to stimuli and was more powerful and

214 direct than a 3-way ANOVA (Dr. G. Oelhert, Statistical Consulting Center, University of

215 Minnesota< Minneapolis, MN). In particular, these matrices allowed us to directly compare

216 passage rates between control and test conditions for each experiment (species) as well as to 
217 calculate overall blockage efficiencies. Once we had determined whether responses to stimuli

218 were significant, we then examined habitation using ANOVAs, before next examining

219 differences between stimuli, species and then groups of species (ex. the carps). These steps are

220 outlined below.

221 For our first step, we examined changes in passage rates using a custom design matrix for

222 each set of experiments written in R and entered into each GLMM. In each GLMM, "fish group

223 number" (test group) was used as a random effect to account for repeated measurements taken

224 from that group of fish. Passage rate data for the pre-test and test periods were transformed to fit

225 a Poisson distribution because these are count data. Assumptions of normality for each GLMM

226 (e.g. that residuals are randomly and normally distributed) were checked visually using a plot of

227 the deviance residuals versus fitted values to test for random distribution of residuals, while

228 over-dispersion was tested by examining the variance of the residuals (McCullagh and Nelder

229 1989). If the variance of the residuals was greater than 2 , we corrected for this hyper-variability

230 by dividing our test statistic by the square root of the dispersion parameter (McCullagh and

231 Nelder 1989) and calculating new p-values for each comparison in that GLMM (this was only

232 necessary for silver and bighead carp). Raw passage rate counts were used as the response

233 variable in the GLMM because our fish moved as individuals in darkness (i.e. fish were not

234 observed to be schooling) and initial evaluations showed that all passage rates were described

235 well by log-linear fits (Tables S1-S10). To determine whether each particular stimulus altered

236 the passage rate of each species, we used a GLMM to compare the log-linear passage rates

237 calculated for each control experiment for that species ( $\mathrm{N}=160$ control periods) with the matched

238 log-linear passage rate calculated for when the stimulus was being tested $(\mathrm{N}=80$ test periods)

$239(\mathrm{P}<0.05)$. In addition, if significance was observed, we compared individual test values with

240 their control values using the GLMM while correcting for multiple comparisons using

241 Bonferroni function $(\mathrm{p}<0.05)$. Finally, mean blockage efficiencies for each species and

242 stimulus were calculated by dividing each test's calculated passage rate for each experiment by

243 the calculated mean passage rate noted during the matched no-treatment control experiment,

244 subtracting the resulting value from 1, and then multiplying that by 100 to get a percent. Mean

245 blockage efficiencies were then calculated.

246 For our second step, we tested for changes in passage rate (habituation) over time for

247 each experiment (species). To accomplish this, we subtracted the each test passage rate value 
248 from its matched pre-test value in experiment, divided that by the pre-test value and multiplied

249 by 100 to derive a set of 8 passage rates for each experiment. Trends in these values were then 250 evaluated using a separate 1-way repeated measures ANOVA (SAS Institute Inc., Cary, NC, 251 USA) for each species and stimulus type, with trial number (1-8) being the main effect, and fish 252 group number (1-10) as a random effect. If a decrease was described ( $p<0.05)$, habituation was 253 noted.

254 Next, for our third step, we determined whether coupling sound with air to make an EBC

255 made it more effective. Mean blockage efficiencies were calculated for each species and 256 stimulus-type, and these values compared by performing a series of Bonferroni-corrected z-tests $257(\mathrm{p}<0.05, \mathrm{n}=10)$. For a fourth step, we sought to determine which fish species were most 258 responsive to each stimulus. To accomplish this, we performed two series of Bonferroni259 corrected z-tests ( $\mathrm{p}<0.05$, corrected for multiple comparisons). The first compared the blockage 260 efficiencies of sound among the ten tested species ( $\mathrm{N}=45$ comparisons), and the second 261 compared the blockage efficiencies of sound coupled with air among the ten tested species $(\mathrm{N}=$ 26245 comparisons). Finally, to determine if hearing ability (specializations) affected fish 263 responsiveness, mean blockage efficiencies were compiled by fish type (i.e. carp, native hearing 264 specialists, native non-hearing specialists) for sound alone and the EBC, and then compared 265 using paired t-tests. These a priori analyses were performed using JMP Pro 13. (SAS Institute 266 Inc., Cary NC, USA) with Bonferroni corrections $(\mathrm{P}<0.05)$.

\section{Results}

Does a cyclic broadband sound effectively block all four species of carp without affecting other

272 fishes, including native hearing specialists?

274 No-treatment control experiments showed that fish passage rates for all 10 species were 275 relatively constant (Fig. 2, 3) and described by log-linear relationships (Supplemental Tables S1276 S10). GLMM analysis next showed that the passage rates of all 10 species were affected by 277 sound $(\mathrm{p}<0.05)$, with 9 species showing a decrease and channel catfish showing an increase 278 (Figs. 2, 3; Table 2, 3). Habitation was noted in three species: the largemouth bass, silver carp, 
and grass carp (29 - 42\% decreases in blockage rate with time; $p<0.05$; Table 2). The overall mean blockage efficiency for all fish was only $44 \pm 37 \%$ (mean \pm SD).

Examining the carps, we noted a high level of variability in the efficacy of sound at blocking the 4 carp species (Fig. 4). While bighead carp and common carp were both effectively 283 blocked by sound ( $86 \pm 48 \%, 83 \pm 27 \%$ respectively) and without habituation (Figs. $2 \mathrm{~B}, 2 \mathrm{H}$;

284 Table 3), silver and grass carp were only weakly affected (31 $\pm 12 \% ; 21 \pm 9 \%$ respectively) with 285 habituation being noted in both instances (p<0.05) (Figs. 2E, 2K; Table 3). Silver carp and grass 286 carp were blocked less than the bighead and common carp ( $\mathrm{p}<0.05$ ), which also did not differ 287 from each other (Table 2), but to the same extent as largemouth bass, a native non-hearing 288 specialist (see below). Taken as whole, the carp were not more affected by sound more than any 289 other group of fish including native hearing non-specialists ( $>0.05$; Table 4).

Responses of native hearing specialists also varied between species. Thus, while golden shiners were blocked moderately effectively $(77 \pm 27 \%)$ and without habituation (Fig. 2N; Table 2 ), channel catfish were strongly attracted ( $\mathrm{p}<0.05$; Fig. 3B), also without habituation ( $p>0.05$;

293 Table 2). Native hearing specialists were not affected by sound more than non-hearing specialists when considered as a group ( $>0.05$; Table 4$)$

Finally, responses of native non-hearing specialists were found to be moderate and less variable and not to differ from each other. Thus, while bluegill sunfish were blocked with moderately effectively by sound alone $(60 \pm 24 \%$; Fig. $3 \mathrm{H})$ without habituation, so were lake sturgeon ( $47 \pm 24 \%$; Fig. $3 \mathrm{~N})$, rainbow trout ( $45 \pm 27 \%$; Fig. $3 \mathrm{~K})$, and largemouth bass ( $34 \pm$ $27 \%)$ which also showed habituation ( $<<0.05)$ (Fig. 3E; Table 2).

Does the cyclic sound block carps more effectively that sound alone and if so, what effects might it have on native fishes, including hearing specialists?

GLMM analysis for each of the 10 species exposed to the EBC showed that the passage rates of all 10 species decreased dramatically when exposed to this multi-modal stimulus ( $<<0.05$; Figs.

308 2, 3). Notably, habituation was not observed for any species (Table 4). Taken as a whole, the 309 mean blockage efficiency for all 10 species to the EBC was $82 \pm 23 \%$, nearly twice that of the 
310 sound. Increases in blockage were noted for all 10 species, which on average differed by $11 \%$ 311 (P<0.05) (Fig. 4).

312 Mean blockage efficiencies for all 4 carp were consistently high $(94 \pm 29 \%)$ for the EBC 313 and while the silver carp was blocked more efficiently than the other 3 carp species ( $p<0.05$;

314 Table 3), the difference was small (2\%) and the other carp species did not differ from each other 315 (p>0.05). While silver carp were blocked $97 \pm 36 \%$ of the time (Fig. 2F), bighead carp were 316 blocked $92 \% \pm 42 \%$ of the time (Fig. 2C), grass carp $95 \pm 24 \%$ of the time (Fig. $2 \mathrm{~L}$ ), and 317 common carp $95 \pm 42 \%$ of the time (Fig. 2I). When the carp were analyzed as a group the carps 318 were blocked more than the native non-hearing specialists $(\mathrm{p}<0.05 \%)$, but not the native hearing 319 specialists ( $>0.05)$ (Table 5).

320 Both of the native hearing specialists were also blocked more efficiently by the EBC than 321 sound alone ( $36 \%$ increase; $\mathrm{p}<0.05$ ). While golden shiners were blocked with high efficiency by 322 sound ( $89 \pm 27 \%$; $\mathrm{p}<0.05)$ and without habituation (Fig. 2P; Table 2), channel catfish were 323 weakly repelled $(\mathrm{P}<0.05$; Fig. 3C) without habituation ( $>0.05$; Table 3 ). Notably, this species 324 had been attracted by the sound alone (41\%, see above).

325 Finally, responses of the native non-hearing specialists were relatively strong $(\mathrm{P}<0.05)$ 326 and did not differ from each other ( $p>0.05$ ), or golden shiners, a hearing specialist (Table 3 ).

327 Thus, while bluegill sunfish were moderately blocked ( $<<0.05)$ by the EBC $(83 \% \pm 30 \%)$ 328 without habituation (Fig. 3I), so were lake sturgeon ( $84 \% \pm 39 \%$ ) (Fig. 3P), rainbow trout ( $81 \%$ $329 \pm 39 \%)$ (Fig. 3P), and largemouth bass ( $88 \pm 48 \%$ ) (Fig. 3I, Table 3).

\section{Discussion}

334 Our laboratory study clearly demonstrated that ensonified bubble curtains (EBCs) are a highly 335 effective way to block the movement of 4 species of invasive carp presently found in North 336 America. However, while the effects of an EBC on all 4 tested carps were substantial (92-97\% 337 blockage), and carp did not habituate to it, we also found that the EBC partially blocked many 338 native fishes, including some lacking hearing specializations. In contrast, the sound projected 339 into the EBC was much less effective when tested on its own for all 10 fish species, especially 
340 the silver and grass carp, which were blocked less than $50 \%$ of the time and habituated.

341 Remarkably, no relationship was noted between whether species had hearing specializations or

342 not and how strongly they were responded by the sound alone. In contrast, responses to the EBC

343 were seen to be weakly carp-specific. We conclude that EBCs offer genuine and unique promise

344 to block invasive carps in rivers, including the highly invasive grass and silver carps, although

345 their effects on the movement of native fishes will need to be addressed.

346 Our most important finding was that the EBC we tested functions as a singularly effective

347 fish deterrent for fish, and carp in particular. All 4 species of the carp we tested, including the

348 silver and grass carp, were nearly completely blocked and without habituation. However,

349 although carps as a group were more affected the EBC, 5 of the other 6 native species we tested

350 were also strongly effected with blockage efficiencies in the $81-89 \%$ range. Thus, although the

351 EBC did not target carps very effectively, it did show promise in that regard. We expect the

352 EBC to have similar effects on other carp including the black carp. Importantly, our results

353 appear replicable; the results of this study are nearly identical to those previously described for

354 both the common carp (95\% vs 99\%, a hearing specialist, and largemouth bass, a non-hearing

355 specialist (88\% vs. 87\%) (Dennis et al. 2019). The reasons for the EBC's high level of overall

356 efficacy likely relate to its multi-modal nature with sound playing an important role (see below).

357 Our finding of extremely high blockage efficiencies are also similar to those noted by a

358 commercial BAFF tests for carp. Taylor et al. (2005) noted an approximate $90 \%$ block of

359 bighead carp in a hatchery raceway. Additionally, Ruebush et al. (2012) noted similarly high

360 blockage rates (seemingly over 95\%) for wild transplanted silver carp in a small creek using an

361 illuminated BAFF under natural conditions although they, like us, noted that a number of native

362 species were also seemingly affected. In any case, the EBCs appear to present new opportunities

363 for reliably controlling carp passage.

364 Our second most important finding was that the sound we tested, and which Dennis et al.

365 (2019) had previous found more effective than another broadband sound, was consistently less

366 effective than the EBC for all 10 species of fish while having little effect on two carps and being

367 plagued by habituation. Especially notable was the fact the nether silver nor grass carps were

368 strongly affected by sound alone. The blockage efficiencies we noted for common carp and

369 largemouth bass were also very similar to those seen previously for sound (83\% vs 79\%; $34 \%$ vs

370 50\%; Dennis et al. 2019). Indeed, our study may be the first study to show such a high level of 
371 repeatability, suggesting that the high level of variation between species is biologically relevant.

372 Especially intriguing was our observation that the channel catfish was strongly attracted to the

373 sound, perhaps reflecting the fact that this species uses a stridulatory sound that might resemble

374 the cyclic sound to communicate (Fine et al. 1995). Also interesting and relevant was the fact

375 that silver and grass carp quickly habituated to this sound after showing a few strong responses.

376 In both cases, we were testing small, young fish that were very active; perhaps these fish were

377 innately more motivated to stay active to find food than to avoid a sound of little apparent

378 significance. Notably, we were able to repeat the silver carp results on a small scale with few

379 unused fish (Fig S1) and all fish were healthy. Although we were the first to test responses of

380 grass carp to sound, others have tested much older/ larger silver carp. While Vetter et al. (2015)

381 noted consistent aversion in a well-lit tank that may have permitted visual learning, Zielinski and

382 Sorensen (2017) tested silver carp in darkness and observed rapid habitation as noted here.

383 Habituation, the tendency of animals to learn to ignore biologically irrelevant stimuli (Rankin et

384 al. 2007) once again appears to be a challenge when testing sound alone (Dennis and Sorensen

385 2020b), at least to the synthetic sounds being employed. We do not believe that there is anything

386 unusual about the broadband cyclic sound we tested because while Dennis et al. (2019) showed it

387 to be more effective than the broadband outboard-motor sound, the difference was not great or

388 qualitatively different. Together, the results of ours studies and others (Putland and Messinger

389 2019) describe responses to sound varying by species and testing scenario, calling into question

390 the value of sound on its own to block carps in rivers.

391 It is interesting and important to speculate why the EBC is so potent because

392 understanding its actions might lead to more effective and/or better targeted EBCs. By

393 previously showing that the effects of an EBC on three species of fish were greater than elicited

394 by either sound or air alone, Dennis et al. (2019) provided compelling evidence that the EBC is

395 multi-modal. The weak relationship we saw between EBC potency and fish hearing ability in our

396 experiment (at least for carp), also argues that factors in addition to sound pressure are important.

397 Likely, particle motion, which is perceived by all fish with otoliths, plays a role in the actions of

398 the EBC because sturgeon, which are insensitive to pressure component of sound, showed

399 surprisingly robust responses to the EBC in our study. However, while the specific

400 characteristics of the sound used in an EBC may be important, it does not appear to be critical or

401 enabling because Dennis et al. (2019) showed the cyclic sound to be only 10\% more effective 
than the outboard motor sound, and quantitatively no different. Likely an EBC is effective

403 because it produces a range of sensory fields that are detected by multiple sensory systems as

404 fish encounter the sharp but complex sound pressure, particle motion, and tactile cues associated 405 near EBCs (Leighton 2002; Leighton et al. 2004; Dennis et al. 2019). We speculate that this 406 combination of sensory cues may be perceived as novel and distinctive by fish which then seek 407 to avoid it because it is stress-inducing. Avoidance is easily achievable because walls of bubbles 408 and the sensory fields associated with them can followed (Dominico 1982; Leighton et al. 2004; 409 Dennis et al. 2019). Sound does not act in such a complex manner. The dynamic, turbulent 410 nature of bubble curtains may also reduce habituation. In this way, fish that hear well (i.e. detect 411 sound pressure via hearing specializations) such as carp, will be especially deterred (unless the 412 sound is actually innately relevant to them), but those that do not hear it will still detect the EBC 413 and avoid it. The carps may be strongly deterred because they share a common set of sensory 414 systems and neurological/ cognitive processes in addition to hearing. If true, then the efficacy of 415 EBC might be increased and targeted by varying the nature of the bubble systems (bubble size, 416 flow and structure) and how sound pressure is coupled to it to drive resonance, as well as by 417 adding other stimuli to match sensory perception in carps. Introducing visual cues (see below) 418 into air curtains might be another possible option, as seen at some commercial BAFFs (Perry et 419 al. 2014). These possibilities will require additional study that should pair high-resolution 420 measurement of all sensory fields associated with EBCs, fish sensory physiology, and fish 421 behavior, both in the laboratory and natural world.

422 Our study had some significant strengths and a few weaknesses. We believe it is the 423 largest study of its kind to test acoustic stimuli as deterrents on fish, having tested 10 species to 424 two stimuli and using over 3000 individuals. We tested only naive (and healthy) fish, although 425 all were immature and unmotivated. Importantly, our findings both replicate and compliment 426 those of Dennis at al. (2019), and support field observations with a BAFF (see below).

427 Nevertheless, like all laboratory studies our study has its limitations. In particular, we only 428 tested small sample of the many taxa of fish found in the Mississippi River and only one type of 429 hearing specialization (i.e. the Webarian apparatus in Ostariphysans). Further, we only tested 430 one water depth and set of lighting conditions (darkness) and some experiment suggest that 431 BAFF are more effective in the day (Welton et al. 2002). We also did not test the effects of 432 water flow which would alter EBC structure and acoustics in rivers. More field tests of EBCs 
433 that include more variables and both carps as well as native fishes are needed to expand on

434 Ruebush et al. (2012)'s pioneering work. Light should be included because carp are deterred by

435 it and when used to illuminate air curtains, it proves additional orientational cues (Dennis and

436 Sorensen 2020b). These tests should consider measuring sensory fields in detail and evaluating

437 how fish approach and hopefully avoid these fields, or some combination thereof. Efforts

438 probably need to consider effects on migrating native fish and also how possible concerns might

439 be addressed by running BAFFs using different types of bubble systems at times that target carp

440 migrations, or perhaps using traps (or fish ladders) in combination with the air curtain so that

441 native fish can be captured and moved upstream while carp are removed. The economic and

442 environmental damage being wrought by invasive carps and the value of maintaining

443 biodiversity argue that these possibilities are well worth exploring (ACRCC 2021).

444 In conclusion, the results of this study, taken together with those of Dennis et al. (2019)

445 in the laboratory and others in the field (Ruebush et al. 2012), demonstrate that EBCs have great

446 and singular promise to stop invasive carps while carrying some risk of disrupting the movement

447 of native fishes. However, based on the present results, sound on its own would appear to little

448 promise at stopping all species of carps, especially grass and silver carps, or effectively targeting

449 any group. Field and laboratory studies of EBCs are urgently needed to elucidate their actions

450 on wild fish while determining how they work and might be improved.

\section{Acknowledgments}

454 We thank the Minnesota Aquatic Invasive Species Research Center for helping administer the

455 project and providing laboratory space. Dr. Andy Turnpenny provided technical support for the

456 laboratory equipment which was leased from Fish Guidance Systems Ltd. without conditions or

457 any expectation. Help with statistical design and analyses were provided by the University of

458 Minnesota's Institute for Research on Statistics and its Applications (IRSA) Statistical

459 Consulting Center. Dan Krause, Rosie Daniels, Kirsten Engseth, Kory Davis, Pheng Lor, Laura

460 Wagner. Austin Abbott, Nicholas Jacob, and Kara Van Lerberghe provided invaluable help with 
461 fish husbandry, running experiments. Clark Dennis provided invaluable help with experimental 462 design, protocols and data analysis.

463

464 Declarations

465 Funding: Funding for this project was provided by the Minnesota Environmental and Natural

466 Resources Trust Fund as recommended by the Legislative-Citizen Commission for Minnesota

467 Resources (LCCMR).

468 Conflicts of interest/ competing interests: Not applicable.

469 Availability of Data and Materials: Data are available from the authors upon request.

470 Code availability: Available from authors upon request

471 Author contributions. This research was conceived by Peter Sorensen who also acquired the

472 funding and edited final drafts of the manuscript. Data collection and analysis was performed by

473 Jane Feely who wrote the first drafts of the manuscript.

474 Ethics approval: Procedures were approved by the University of Minnesota Institutional

475 Animal Care and Use Committee (Protocol: 1712-35381A).

476

477

478

479 References

480 Asian Carp Regional Coordinating Committee (ACRCC) (2021) Asian Carp Action Plan $481 \quad$ available at https://www.asiancarp.us/

482 Banet NV, Fieberg J, Sorensen PW (2021) Migration, homing and spatial ecology of common 483 carp in interconnected lakes. Ecol Fresh Fish DOI10.1111/eff12622

484 Brevik I, Kristiansen O (2002) The flow in and around air-bubble plumes. Int. J. Multiph. Flow. 
486 Chapman DC, Hoff MH (2011) Invasive Asian carps in North America. American Fisheries Society, Bethesda, MD

488 Claus A, Sorensen PW (2019) Chemical cues which include amino acids mediate species489 specific feeding behavior in invasive filter-feeding bigheaded carps. J. Chem Ecol, 43:374-384.

491 Cudmore B, Mandrak N (2004) Biological Synopsis of Grass Carp (Ctenopharyngodon idella). Can Manuscript Rept Fish Aquat Sci 2705

493 DeGrandchamp KL, Garvey JE, Colombo RE (2008) Movement and habitat selection by 494 invasive Asian carps in a large river. Trans Amer Fish Soc 137:45-56.

495 Dennis CE, Zielinski DP, Sorensen PW (2019) A complex sound coupled with an air curtain blocks invasive carp passage without habituation in a laboratory flume. Biol Invas 21:2837-2855

Dennis CE, Sorensen PW (2020a) High-intensity light blocks Bighead Carp in a laboratory flume. Manag Biol Invas 11:441-460.

500 Dennis CE, Sorensen PW (2020b) Common carp are initially repelled by a broadband outboard 501 motor sound in a lock chamber but habituate rapidly. N Amer J Fish Manag 40:14991509.

503 Dominico SN (1982) Acoustic wave propagation in air-bubble curtains in water- part 1. History and theory. Geophysics 37:345-353.

505 Dong S and Li D (1994) Comparative studies on the feeding selectivity of silver carp Hypophthalmichthys molitrix and bighead carp Aristichthys nobilis. J Fish Biol 44:612-626. 
508 Embke H, Kocovsky P, Richter C, Pritt J, Mayer C, Qian S (2016) First direct confirmation of 509 grass carp spawning in a Great Lakes tributary. J Great Lakes Res 42:899-903.

510 Fay R, Tavolga W (2012). Sensory biology of aquatic animals. Springer Science \& Business

$511 \quad$ Media.

512 Fine M, McElroy D, Rafi J, King C, Loesser K, Newton S (1995) Lateralization of

513 Pectoral stridulation sound production in the channel catfish. Physiol Behav 60:753-757.

514 Harris C, Brenden T, Vandergoot C, Faust M, Herbst S, Krueger C (2021) Tributary use and 515 large-scale movements of grass carp in Lake Erie. J Great Lakes Res 47:48-58.

516 Kolar C, Chapman D, Courtenay W, Housel C, Williams J, Jennings D (2007) Bigheaded carps:

517 A biological synopsis and environmental risk assessment. American Fisheries Society, $518 \quad$ Bethesda, MD

519 Lamer JT, Dolan CR, Petersen JL, Chick JL, Epifanio JM (2010) Introgressive hybridization 520 between bighead and silver carp in the Mississippi and Illinois rivers. N Amer J Fish $521 \quad$ Manage 30:1452-1461.

522 Leighton, TG (2012). The acoustic bubble. Academic Press, London

523 Leighton, TG, Richards SD, White PR (2004) Trapped within a "wall of sound." Accoust Bull $524 \quad 29: 24-29$.

525 Lu Z, Popper A, Fay R (1996) Behavioral detection of acoustic particle motion by a teleost fish 526 (Astronotus ocellatus): sensitivity and directionality. J Comp Physiol 179:227-233.

527 McCullagh P, Nelder J. 1989. Binary data. Generalized linear models: 98-148. Springer US.

528 Murchy K, Vetter B, Brey M, Amberg J, Gaikowski M, Mensinger A (2016). Not all carp are 529 created equal: Impacts of broadband sound on common carp swimming behavior. In 

Society of America.

532 Nico L, Jelks H (2011). The Black Carp in North America: An Update. American Fisheries $533 \quad$ Society Symposium 74:89-104.

534 Noatch M, Suski C (2012) Non-physical barriers to deter fish movements. Env Rev 20: 1-12.

535 Perry RW, Romine JG, Adams NS, Blake AR, Burau JR, Johnston SV, Liedtke TL (2014) Using a non-physical behavioural barrier to alter migration routing of juvenile chinook salmon in the Sacramento-San Joaquin River delta. River Res Appl 30:192-203.

538 Popper AN, Carlson T (1998) Application of sound and other stimuli to control fish behavior. $539 \quad$ Trans Amer Fish Soc 127:673-707.

540 Putland R, Mensinger A (2019) Acoustic deterrents to manage fish populations. Rev Fish Biol $541 \quad$ Fish 29:789-807.

542 Rankin CT, Abrams R, Barry S, Bhatnagar D, Clayton J, Colombo G, Coppola M, Geyer D, 543 Glanzman S, Marsland F, McSweeney F (2009). Habituation revisited: an updated and 544 revisedcdescription of the behavioral characteristics of habituation. Neurobiol Learn $545 \quad$ Mem 92:135-138.

546 Reeves A (2019) Overrun: Dispatches from the Asian Carp Crisis. Toronto: ECW Press.

547 Ruebush B, Sass G, Chick J, Stafford J (2012). In-situ tests of sound-bubble-strobe light barrier 548 technologies to prevent range expansions of Asian carp. Aquat Invasions 7:37-48.

549 Smith ME, Kane AS, Popper AN (2004). Noise-induced stress response and hearing loss in 550 goldfish (Carassius auratus). J Exp Biol 207:427-435.

551 Stell E, Hoover J, Fuller L, Parsons G (2019) Analyzing leap characteristics and water 552 escape velocities of Silver Carp using in situ video analysis. N Amer J 
Fish Manag 40:163-174.

554 Sorensen PW, Bajer PB (2011) Common carp. In: Biological Invasions, No. 3. Berkley and 555 Los Angeles editors: University of California Press.

556 Taylor RM, Pegg MA, Chick JH (2005) Response of a bighead carp to a bioacoustics

557 behavioural fish guidance system. Fish Manag Ecol 12:283-286.

558 Vetter BJ, Cupp AR, Fredricks KT, Gaikowski MP, Mensinger AF (2015). Acoustical deterrence $559 \quad$ of silver carp (Hypophthalmichthys molitrix). J. Biol Invas 17:3383-3392.

560 Welton JS, Beaumont WRC, Clarke RT (2002) The efficacy of air, sound, and acoustic bubble 561 screens in deflecting Atlantic salmon, Salmo salar L., smolts in the River Frome, UK. $562 \quad$ Fish Manag Ecol 9:11-18.

563 Zielinski DP, Sorensen PW (2016) Field test of a bubble curtain deterrent system for common 564 carp. Fish Manag Ecol 22:181-184.

565 Zielinski DP, Sorensen PW (2017) Silver, bighead, and common carp orient to acoustic 566 particle motion when avoiding a complex sound. PLOS One.12:e0180110

567 Zielinski DP, Sorensen PW (2021) Numeric simulation demonstrates that the upstream 568 movement of invasive bigheaded carp can be blocked at sets of Mississippi River 569 locks-and-dams using a combination of optimized spillway gate operations, lock 570 deterrents, and carp removal. Fishes 6, 10. https://doi.org/10.3390/fishes6020010

571 Zielinski DP, Voller VR, Sorensen PW (2018) A physiologically inspired agent-based approach

572 to model upstream passage of invasive fish at a lock-and-dam. Ecol Model 382:18-32.

573 Zielinski DP, Voller VR, Svendsen JC, Hondzo M, Mensinger AF, Sorensen PW (2014).

574 Laboratory experiments demonstrate that bubble curtains can effectively inhibit 575 movement of common carp. Ecol Eng 67:95-103. 
576 


\section{Figure legends}

579 Fig. 1 Schematic drawing of an overhead view of the elliptical laboratory flume used by this 580 study and by Dennis et al. (2019) as well as Dennis and Sorensen (2020b). Pairs of speakers 581 were placed in mid-channel along with an air injection system. Panels A-F to the right show 582 plan views of sound pressure (RMS) levels in $\mathrm{dB}$ (ref $1 \mu \mathrm{Pa}$ ) at different frequency ranges for 583 sound alone (A, C, F) and the ensonified bubble curtain (EBC) (B, D. G) (see text for details).

585 Fig. 2 Mean passage rates \pm standard deviation (SD) (i.e. number of passages per 6-min pre-test 586 or test period with stimulus) of 5 species of fish with hearing specializations (4 carps and 1 587 native hearing specialist) during control conditions (no stimulus), sound only, and sound coupled 588 with air as an ensonified bubble curtain (EBC) across time. Test number is indicated on the x589 axis and differences between individual pre- and test passage rates are shown by an asterisk 590 ( $\mathrm{p}<0.05$; see text): (A). Bighead carp - control; (B) Bighead carp - sound only; (C). Bighead carp 591 - EBC; (D). Silver carp - control; (E) Silver carp - sound only; (F). Silver carp - EBC; (G).

592 Common carp - control; (H) Common carp - sound only; (I) Common carp - EBC; (J). Grass 593 carp - control; (K) Grass carp - sound only; (L). Grass carp, - EBC; (M). Golden shiners- control; 594 (N) Golden shiners - sound only; (O). Golden shiners - EBC. Note that scale is different fro 595 silver and grass carp as they were more active.

596

597 Fig. 3 Mean passage rates \pm standard deviation (SD) (i.e. number of passages per 6-min pre-test 598 or test period with stimulus) of 1 species of native hearing specialist and 4 native non-hearing 599 specialists during control conditions (no stimulus), when tested with sound alone, and sound 
600 coupled with air as an ensonified bubble curtain (EBC) across time. Test number is indicated on 601 the $\mathrm{x}$-axis and differences between individual pre- and test passage rates are shown by an asterisk 602 (p<0.05; see text): (A). Channel catfish - control; (B) Channel catfish - sound only; (C). Channel 603 catfish - EBC; (D). Largemouth bass - control; (E) Largemouth bass - sound only; (F).

604 Largemouth bass - EBC; (G). Bluegill sunfish - control; (H) Bluegill sunfish - sound only; (I)

605 Bluegill sunfish - EBC; (J). Rainbow trout- control; (K) Rainbow trout - sound only; (L).

606 Rainbow trout - EBC; (M). Lake sturgeon - control; (N) Lake sturgeon - sound only; (O). Lake 607 sturgeon $-\mathrm{EBC}$.

608

609 Fig. 4 Mean blockage efficiencies \pm standard deviation (SD) of 10 species of fish to sound alone 610 (light bars) or an ensonified bubble curtain (EBC, dark bars). Rates for each species were 611 compared with each other (see Tables 2 and 3) and between sound and EBC (see text).

612 Differences for the latter $(\mathrm{p}<0.05)$ are noted with an asterisk.

613 
614 Table 1 Species tested, their taxonomic group, origin, size, and whether they possess hearing

615 specializations.

\begin{tabular}{|c|c|c|c|c|c|}
\hline Fish Species & Family & $\begin{array}{l}\text { Native } \\
\text { or Non- } \\
\text { native }\end{array}$ & $\begin{array}{l}\text { Length } \\
(\text { mean } \pm \\
\text { SD) } \mathrm{cm}\end{array}$ & $\begin{array}{l}\text { Weight } \\
(\text { mean } \pm \\
\text { SD) } g\end{array}$ & $\begin{array}{l}\text { Hearing } \\
\text { Specialization } \\
\text { (Yes or No) }\end{array}$ \\
\hline $\begin{array}{l}\text { Bighead carp (BC) } \\
\text { (Hypophthalmichthys } \\
\text { nobilis) }\end{array}$ & Cyprinidae & $\begin{array}{l}\text { Non- } \\
\text { native }\end{array}$ & $142 \pm 15$ & $\begin{array}{l}33.06 \pm \\
8.48\end{array}$ & Yes \\
\hline $\begin{array}{l}\text { Silver carp (SC) } \\
\text { (Hypophthalmichthys } \\
\text { molitrix) }\end{array}$ & Cyprinidae & $\begin{array}{l}\text { Non- } \\
\text { native }\end{array}$ & $85 \pm 11$ & $\begin{array}{l}5.58 \pm \\
1.55\end{array}$ & Yes \\
\hline $\begin{array}{l}\text { Common carp }(\mathrm{CC}) \\
\text { (Cyprinus carpio) }\end{array}$ & Cyprinidae & $\begin{array}{l}\text { Non- } \\
\text { native }\end{array}$ & $110 \pm 19$ & $\begin{array}{l}20.22 \pm \\
10.59\end{array}$ & Yes \\
\hline $\begin{array}{l}\text { Grass carp (GC) } \\
\text { (Ctenopharyngodon } \\
\text { idella) }\end{array}$ & Cyprinidae & $\begin{array}{l}\text { Non- } \\
\text { native }\end{array}$ & $133 \pm 18$ & $\begin{array}{l}24.34 \pm \\
9.78\end{array}$ & Yes \\
\hline $\begin{array}{l}\text { Golden shiners (GS) } \\
\text { (Notemigonus } \\
\text { crysoleucas) }\end{array}$ & Cyprinidae & Native & $88 \pm 10$ & $\begin{array}{l}6.52 \pm \\
3.18\end{array}$ & Yes \\
\hline $\begin{array}{l}\text { Channel catfish }(\mathrm{CH}) \\
\text { (Ictalurus punctatus) }\end{array}$ & Ictaluridae & Native & $138 \pm 19$ & $\begin{array}{l}23.62 \pm \\
8.89\end{array}$ & Yes \\
\hline $\begin{array}{l}\text { Largemouth bass (LB) } \\
\text { (Micropterus salmoides) }\end{array}$ & Centarchidae & Native & $124 \pm 23$ & $\begin{array}{l}24.76 \pm \\
13.54\end{array}$ & No \\
\hline $\begin{array}{l}\text { Bluegill sunfish (BS) } \\
\text { (Lepomis macrochirus) }\end{array}$ & Centrarchidae & Native & $106 \pm 15$ & $\begin{array}{l}20.75 \pm \\
10.19\end{array}$ & No \\
\hline $\begin{array}{l}\text { Rainbow trout (RT) } \\
\text { (Oncorhynchus mykiss) }\end{array}$ & Salmonidae & Native & $130 \pm 13$ & $\begin{array}{l}24.50 \pm \\
5.24\end{array}$ & No \\
\hline $\begin{array}{l}\text { Lake sturgeon (LS) } \\
\text { (Acipenser fulvescens) }\end{array}$ & Acipenseridae & Native & $162 \pm 18$ & $\begin{array}{l}12.75 \pm \\
3.14\end{array}$ & No \\
\hline
\end{tabular}


Table 2. Effects of sound alone on the passage rates of 10 species of fish. Species, mean passage rates for the no-treatment control and test periods (calculated from individual trials), mean blockage efficiency (from GLMM), habituation, comparisons between the blockage efficiencies between the 10 species $(\mathrm{p}<0.05)$. Mean \pm Standard Deviation (SD).

\begin{tabular}{|c|c|c|c|c|c|c|}
\hline Species & $\begin{array}{l}\text { Mean } \\
\text { Passage } \\
\text { Rate } \\
\text { Control }\end{array}$ & $\begin{array}{l}\text { Mean } \\
\text { Passage } \\
\text { Rate } \\
\text { Sound }\end{array}$ & $\begin{array}{l}\text { Mean } \\
\text { Blockage } \\
\text { Efficiency }\end{array}$ & $\begin{array}{l}\text { Habituation } \\
\text { Measured } \\
\text { (Yes or No) }\end{array}$ & $\begin{array}{l}\text { Blocked More } \\
\text { Than: }\end{array}$ & $\begin{array}{l}\text { Blocked } \\
\text { Less Than: }\end{array}$ \\
\hline $\begin{array}{l}\text { Bighead Carp } \\
\text { (BC) }\end{array}$ & $14 \pm 8$ & $2 \pm 2^{*}$ & $86 \pm 48 \%$ & No & $\begin{array}{l}\mathrm{GC}, \mathrm{SC}, \mathrm{CH}, \\
\mathrm{LS}, \mathrm{RT}, \mathrm{LB}, \mathrm{BS}\end{array}$ & N/A \\
\hline $\begin{array}{l}\text { Silver Carp } \\
(\mathrm{SC})\end{array}$ & $30 \pm 20$ & $35 \pm 21 *$ & $31 \pm 12 \%$ & Yes & $\mathrm{CH}$ & $\begin{array}{l}\text { BC, CC, } \\
\text { GS, BS }\end{array}$ \\
\hline $\begin{array}{l}\text { Common Carp } \\
\text { (CC) }\end{array}$ & $16 \pm 9$ & $3 \pm 4^{*}$ & $83 \pm 27 \%$ & No & $\begin{array}{l}\mathrm{GC}, \mathrm{SC}, \mathrm{CH}, \\
\mathrm{LS}, \mathrm{RT}, \mathrm{LB}, \mathrm{BS}\end{array}$ & N/A \\
\hline $\begin{array}{l}\text { Grass Carp } \\
(\mathrm{GC})\end{array}$ & $57 \pm 14$ & $46 \pm 20 *$ & $21 \pm 9 \%$ & Yes & $\mathrm{CH}$ & $\begin{array}{l}\text { BC, CC, } \\
\text { GS, LS, } \\
\text { RT, LB, } \\
\text { BS }\end{array}$ \\
\hline $\begin{array}{l}\text { Golden Shiners } \\
(\mathrm{GS})\end{array}$ & $10 \pm 5$ & $4 \pm 3^{*}$ & $77 \pm 27 \%$ & No & $\begin{array}{l}\mathrm{GC}, \mathrm{SC}, \mathrm{CH}, \\
\mathrm{LS}, \mathrm{RT}, \mathrm{LB}, \mathrm{BS}\end{array}$ & N/A \\
\hline $\begin{array}{l}\text { Channel Catfish } \\
\text { (CC) }\end{array}$ & $11 \pm 5$ & $19 \pm 7^{+}$ & $-41 \pm 15 \%$ & No & N/A & $\begin{array}{l}\text { BC, CC, } \\
\text { GC, SC, } \\
\text { GS, LS, } \\
\text { RT, LB, } \\
\text { BS }\end{array}$ \\
\hline $\begin{array}{l}\text { Largemouth } \\
\text { Bass (LB) }\end{array}$ & $11 \pm 10$ & $3 \pm 3^{*}$ & $34 \pm 27 \%$ & Yes & $\mathrm{CH}$ & $\begin{array}{l}\mathrm{BC}, \mathrm{CC}, \\
\mathrm{GS}, \mathrm{BS}\end{array}$ \\
\hline $\begin{array}{l}\text { Bluegill } \\
\text { Sunfish (BS) }\end{array}$ & $8 \pm 3$ & $3 \pm 2 *$ & $60 \pm 24 \%$ & No & $\begin{array}{l}\mathrm{GC}, \mathrm{SC}, \mathrm{CH}, \\
\mathrm{LB}\end{array}$ & $\begin{array}{l}\mathrm{BC}, \mathrm{CC}, \\
\mathrm{GS}\end{array}$ \\
\hline $\begin{array}{l}\text { Rainbow Trout } \\
\text { (RT) }\end{array}$ & $7 \pm 5$ & $5 \pm 4^{*}$ & $45 \pm 27 \%$ & No & $\mathrm{GC}, \mathrm{CH}$ & $\begin{array}{l}\mathrm{BC}, \mathrm{CC}, \\
\mathrm{GS}\end{array}$ \\
\hline $\begin{array}{l}\text { Lake Sturgeon } \\
\text { (LS) }\end{array}$ & $8 \pm 6$ & $5 \pm 4^{*}$ & $47 \pm 24 \%$ & No & $\mathrm{GC}, \mathrm{SC}, \mathrm{CH}$ & $\begin{array}{l}\mathrm{BC}, \mathrm{CC}, \\
\mathrm{GS}\end{array}$ \\
\hline
\end{tabular}

*decrease in passage rate vs. control rate measured by GLMM $(\mathrm{P}<0.05) ;+$ significant increase; N/A= no affect 
Table 3 Effects of the ensonified bubble curtain (EBC) on passage rates of 10 species of fish. Species, mean passage rates for no-treatment control and test periods (calculated from individual trials), mean blockage efficiency (from GLMM), habituation, comparisons between the blockage efficiencies of the 10 species $(\mathrm{p}<0.05)$. Means \pm Standard Deviation $(\mathrm{SD})$.

\begin{tabular}{|c|c|c|c|c|c|c|c|}
\hline Species & $\begin{array}{l}\text { Mean } \\
\text { Passage } \\
\text { Rate } \\
\text { Control }\end{array}$ & $\begin{array}{l}\text { Mean } \\
\text { Passage } \\
\text { Rate } \\
\text { EBC }\end{array}$ & $\begin{array}{l}\text { Mean } \\
\text { Blockage } \\
\text { Efficiency }\end{array}$ & $\begin{array}{l}\text { Habitu } \\
\text { ation? } \\
\text { (Yes or } \\
\text { No) }\end{array}$ & $\begin{array}{l}\text { More } \\
\text { Effective } \\
\text { Than } \\
\text { Sound? }\end{array}$ & $\begin{array}{l}\text { Blocked More } \\
\text { Than: }\end{array}$ & $\begin{array}{l}\text { Blocked } \\
\text { less } \\
\text { Than: }\end{array}$ \\
\hline $\begin{array}{l}\text { Bighead } \\
\text { Carp (BC) }\end{array}$ & $14 \pm 8$ & $1 \pm 0.6^{*}$ & $92 \pm 53 \%$ & No & Yes & $\mathrm{CH}, \mathrm{RT}$ & $\mathrm{SC}$ \\
\hline $\begin{array}{l}\text { Silver Carp } \\
(\mathrm{SC})\end{array}$ & $30 \pm 20$ & $1 \pm 3^{*}$ & $97 \pm 36 \%$ & No & Yes & $\begin{array}{l}\mathrm{BC}, \mathrm{CC}, \mathrm{GS}, \\
\mathrm{BS}, \mathrm{LS}, \mathrm{RT}, \\
\mathrm{LB}, \mathrm{GC}, \mathrm{CH}\end{array}$ & N/A \\
\hline $\begin{array}{l}\text { Common } \\
\text { Carp (CC) }\end{array}$ & $16 \pm 9$ & $0.9 \pm 1 *$ & $95 \pm 42 \%$ & No & Yes & $\begin{array}{l}\text { CH, GS, LS, } \\
\text { RT, LB, BS }\end{array}$ & $\mathrm{SC}$ \\
\hline $\begin{array}{l}\text { Grass Carp } \\
\text { (GC) }\end{array}$ & $57 \pm 14$ & $3 \pm 3 *$ & $95 \pm 24 \%$ & No & Yes & $\begin{array}{l}\text { CH, GS, LS, } \\
\text { RT, LB, BS }\end{array}$ & $\mathrm{SC}$ \\
\hline $\begin{array}{l}\text { Golden } \\
\text { Shiners } \\
\text { (GS) }\end{array}$ & $10 \pm 5$ & $1 \pm 0.5^{*}$ & $89 \pm 36 \%$ & No & Yes & $\mathrm{CH}$ & $\begin{array}{l}\mathrm{CC}, \mathrm{GC}, \\
\mathrm{SC}\end{array}$ \\
\hline $\begin{array}{l}\text { Channel } \\
\text { Catfish } \\
\text { (CT) }\end{array}$ & $11 \pm 5$ & $10 \pm 3^{*}$ & $19 \pm 18 \%$ & No & Yes & N/A & $\begin{array}{l}\mathrm{BC}, \mathrm{CC}, \\
\mathrm{GC}, \mathrm{BS}, \\
\mathrm{LS}, \mathrm{RT}, \\
\mathrm{LB}, \mathrm{SC}, \\
\mathrm{GC}\end{array}$ \\
\hline $\begin{array}{l}\text { Largemouth } \\
\text { Bass (LB) }\end{array}$ & $11 \pm 10$ & $0.8 \pm 1 *$ & $88 \pm 48 \%$ & No & Yes & $\mathrm{CH}$ & $\begin{array}{l}\mathrm{CC}, \mathrm{GC}, \\
\mathrm{GC}\end{array}$ \\
\hline $\begin{array}{l}\text { Bluegill } \\
\text { Sunfish (BS }\end{array}$ & $8 \pm 3$ & $2 \pm 2 *$ & $83 \pm 30 \%$ & No & Yes & $\mathrm{CH}$ & $\begin{array}{l}\mathrm{CC}, \mathrm{GC}, \\
\mathrm{SC}\end{array}$ \\
\hline $\begin{array}{l}\text { Rainbow } \\
\text { Trout (RT) }\end{array}$ & $7 \pm 5$ & $1 \pm 2 *$ & $81 \pm 39 \%$ & No & Yes & $\mathrm{CH}$ & $\begin{array}{l}\mathrm{CC}, \mathrm{GC}, \\
\mathrm{SC}\end{array}$ \\
\hline $\begin{array}{l}\text { Lake } \\
\text { Sturgeon } \\
\text { (LS) }\end{array}$ & $8 \pm 6$ & $1 \pm 1 *$ & $84 \pm 39 \%$ & No & Yes & $\mathrm{CH}$ & $\begin{array}{c}\mathrm{CC}, \mathrm{GC}, \\
\mathrm{SC}\end{array}$ \\
\hline
\end{tabular}


Table 4. Effects of sound alone on different groups of fish (carp, native hearing specialists, native non-hearing specialists). No differences $(\mathrm{P}>0.05)$ were noted.

\begin{tabular}{llc}
\hline Groups Being Compared & $\begin{array}{l}\text { Mean } \\
\text { Blockage } \\
\text { Efficiency }\end{array}$ & $\begin{array}{l}\text { Difference } \\
(\text { Prob }>|t|)\end{array}$ \\
\hline Carp vs. Native hearing specialists & $\begin{array}{l}55 \pm 34 \% \text { vs. } \\
18 \pm 83 \%\end{array}$ & 0.6405 \\
Carp vs. Native non-hearing specialists & $55 \pm 34 \%$ vs. & 0.6552 \\
& $46 \pm 11 \%$ & \\
Carp + Native hearing specialists vs. & $43 \pm 49 \%$ vs. & 0.8670 \\
Native non-hearing specialists & $46 \pm 10.7 \%$ & \\
& & \\
\hline
\end{tabular}


Table 5. Effects of the ensonified bubble curtain (EBC) on different groups of fish (carp, native hearing specialists, native non-hearing specialists). Difference is noted at $\mathrm{p}<0.05$.

\begin{tabular}{lll}
\hline Groups Being Compared & $\begin{array}{l}\text { Mean } \\
\text { Blockage } \\
\text { Efficiencies }\end{array}$ & $\begin{array}{l}\text { Difference } \\
(\text { Prob }>|t|)\end{array}$ \\
\hline Carp vs. Native hearing specialists & $95 \pm 29 \%$ vs. & 0.4516 \\
& $54 \pm 42 \%$ & \\
Carp vs. Native Non-hearing specialists & $95 \pm 31 \%$ vs. & $0.0015^{*}$ \\
& $84 \pm 84 \%$ & \\
Carp + Native hearing specialists & $81 \pm 31 \%$ vs. & 0.8304 \\
vs. Native non-hearing specialists & $84 \pm 3 \%$ & \\
& & \\
*P $<0.05$ & &
\end{tabular}



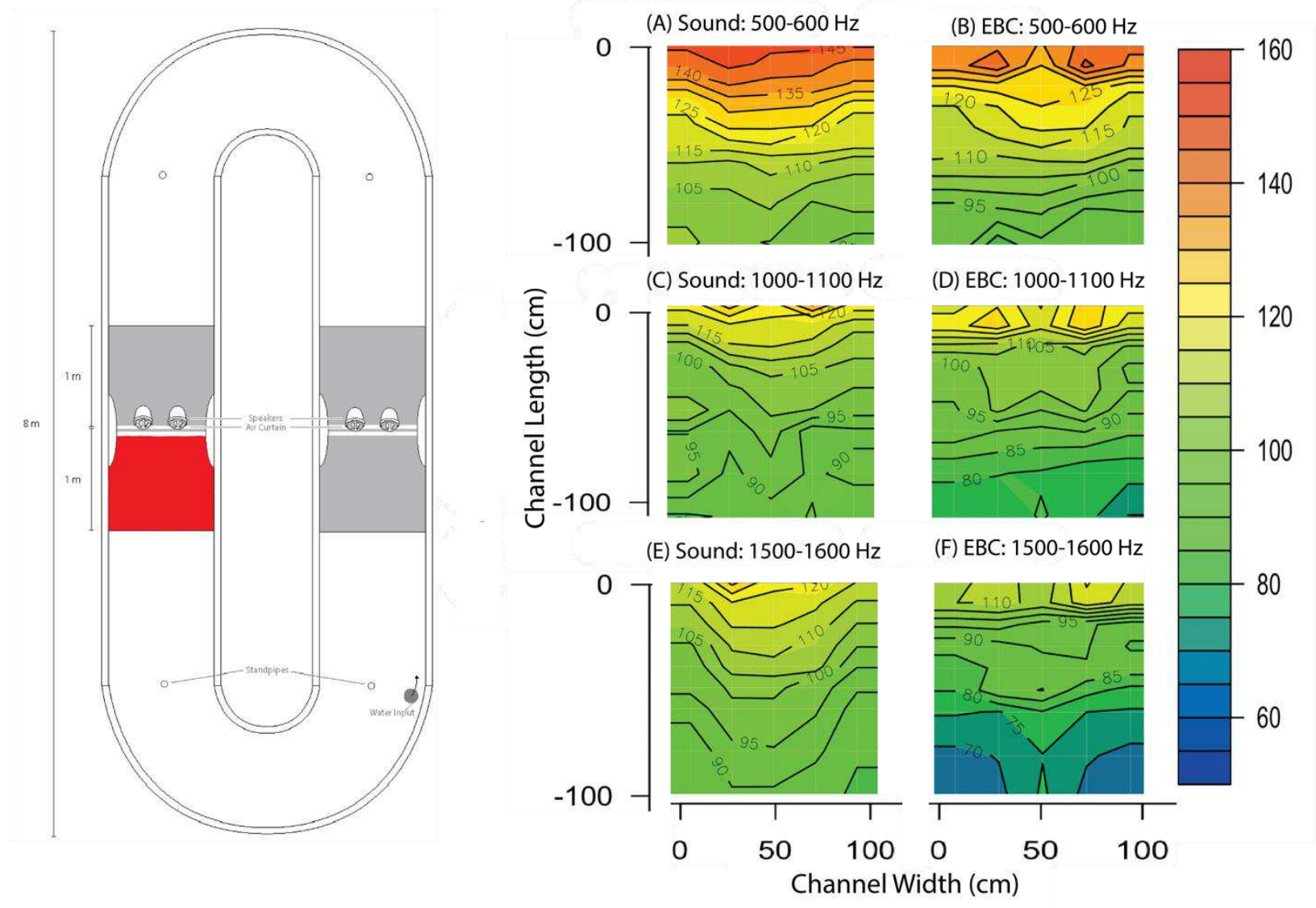

Fig 1 
BIGHEAD CARP
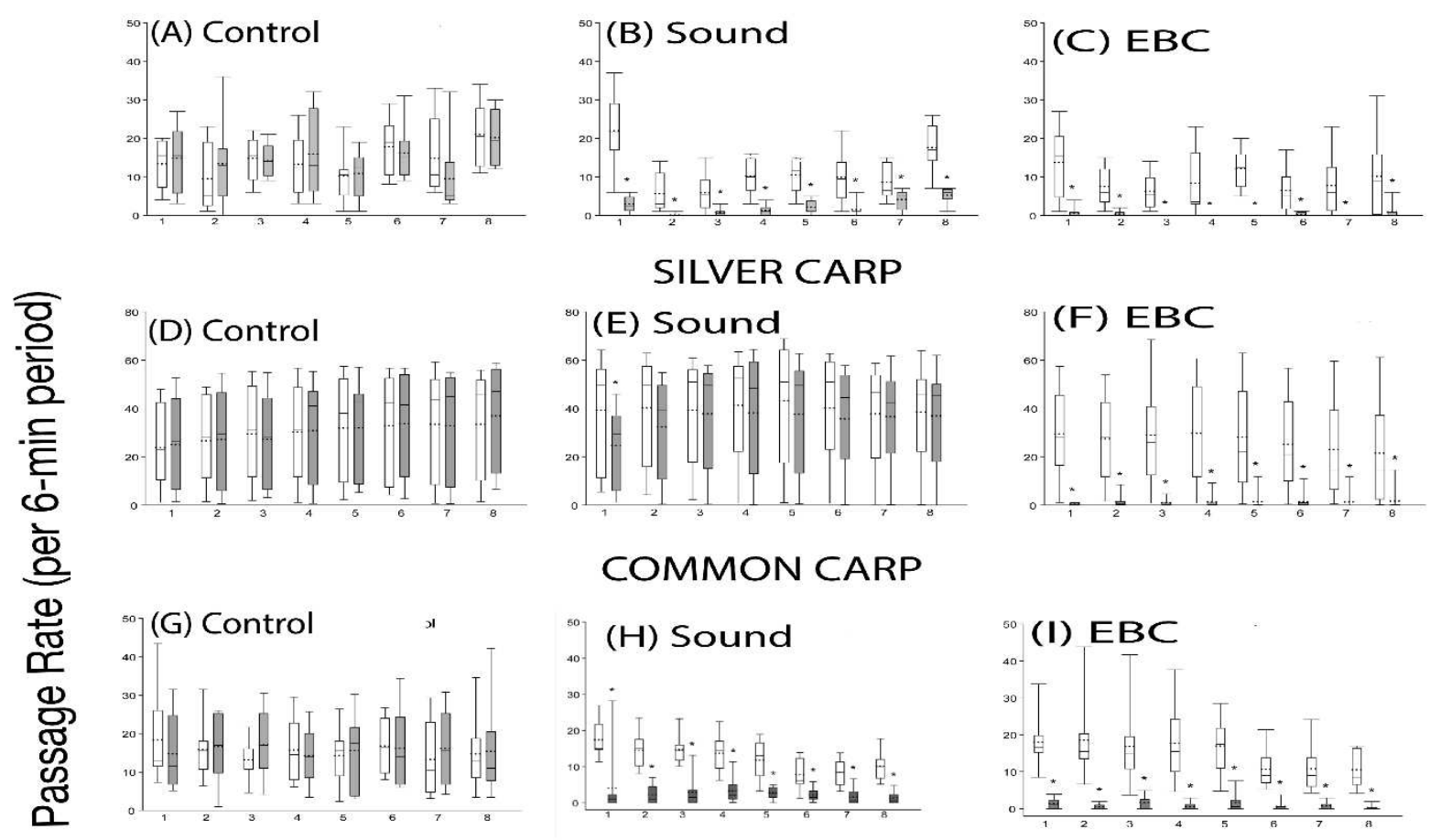

\section{${ }^{80}$ (D) Control}

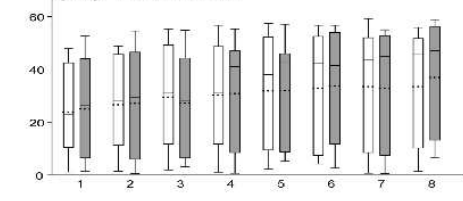

SILVER CARP

${ }^{80}$ (E) Sound

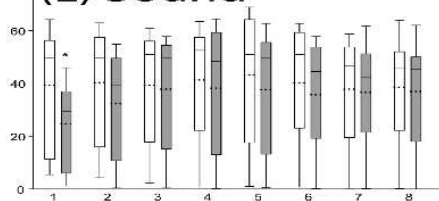

${ }^{\infty}$ (F) EBC

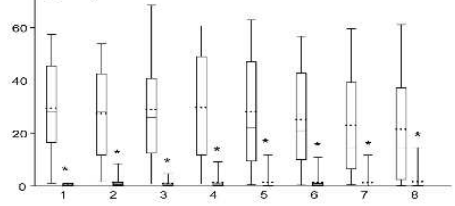

\section{COMMON CARP}

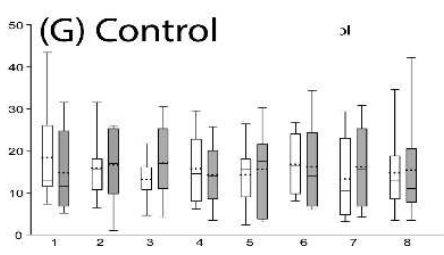

(H) Sound

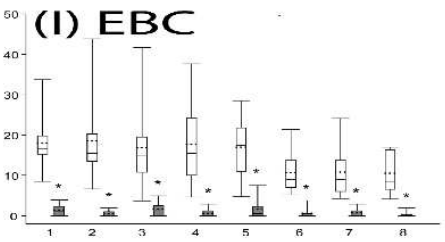

GRASS CARP
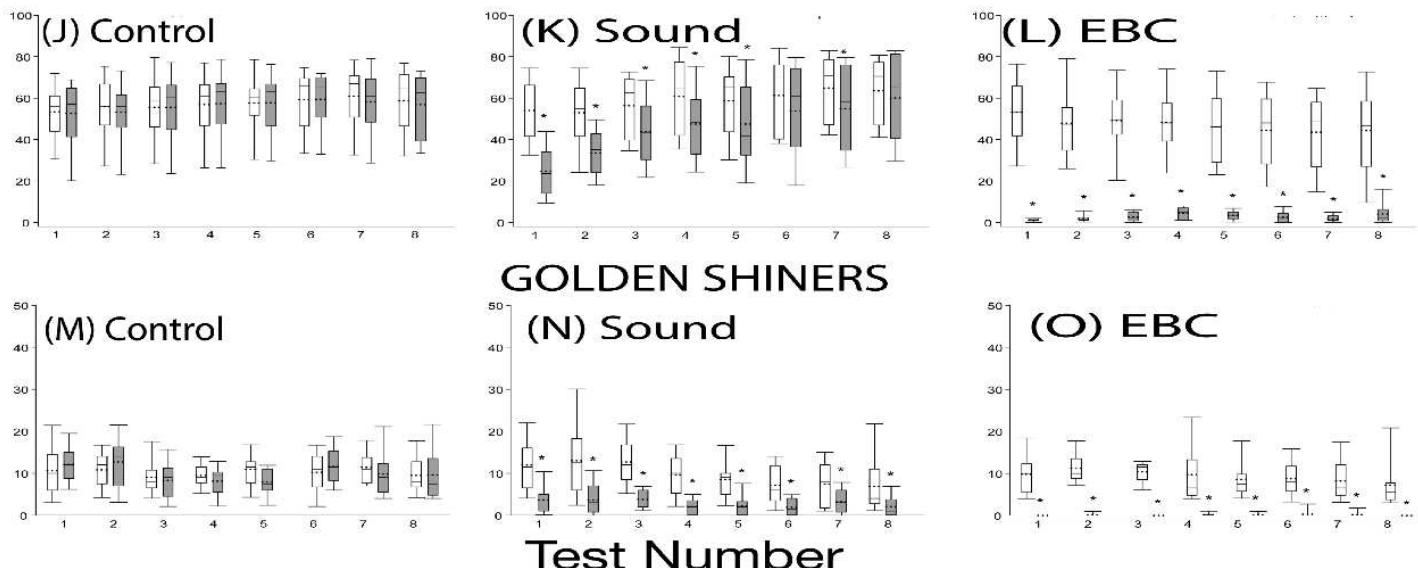

Fig. 2 


\section{CHANNEL CATFISH}
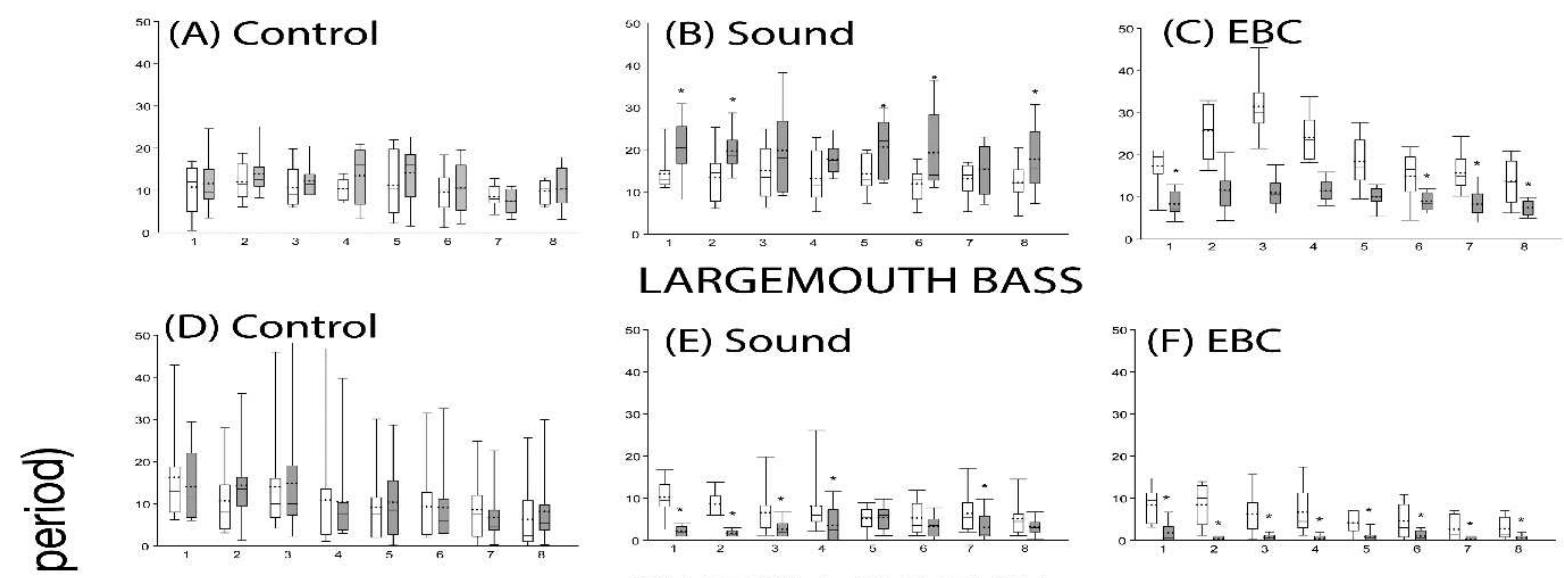

\section{BLUEGILL SUNFISH}
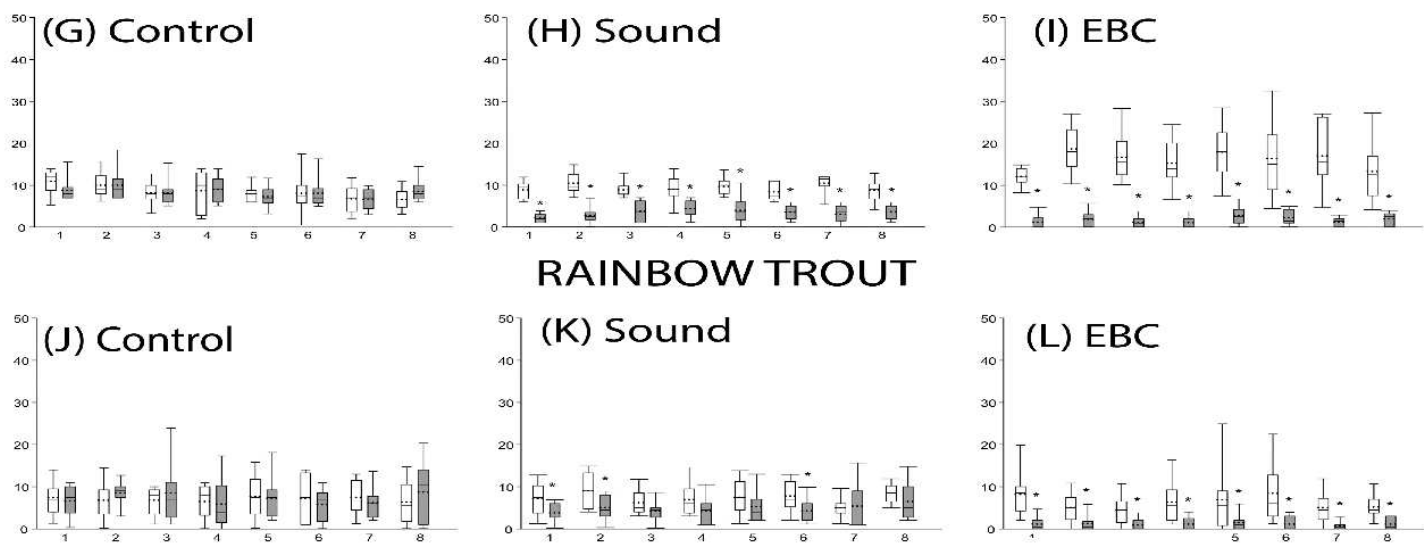

\section{RAINBOW TROUT}

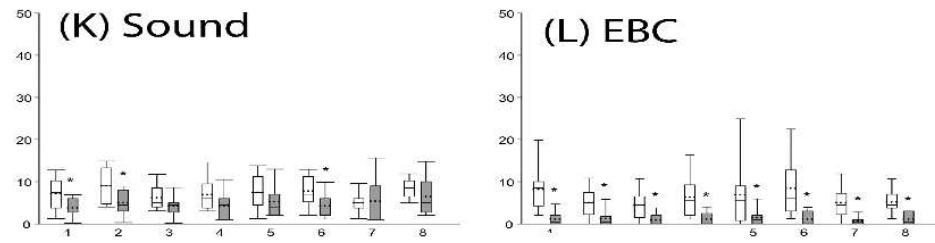

\section{LAKE STURGEON}
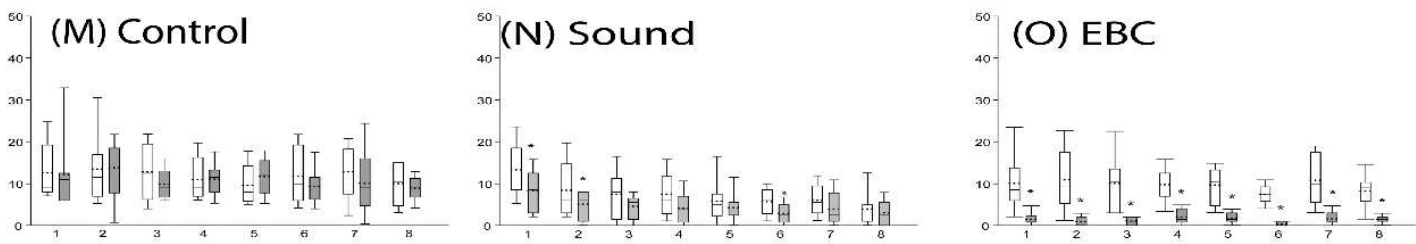

Test Number 


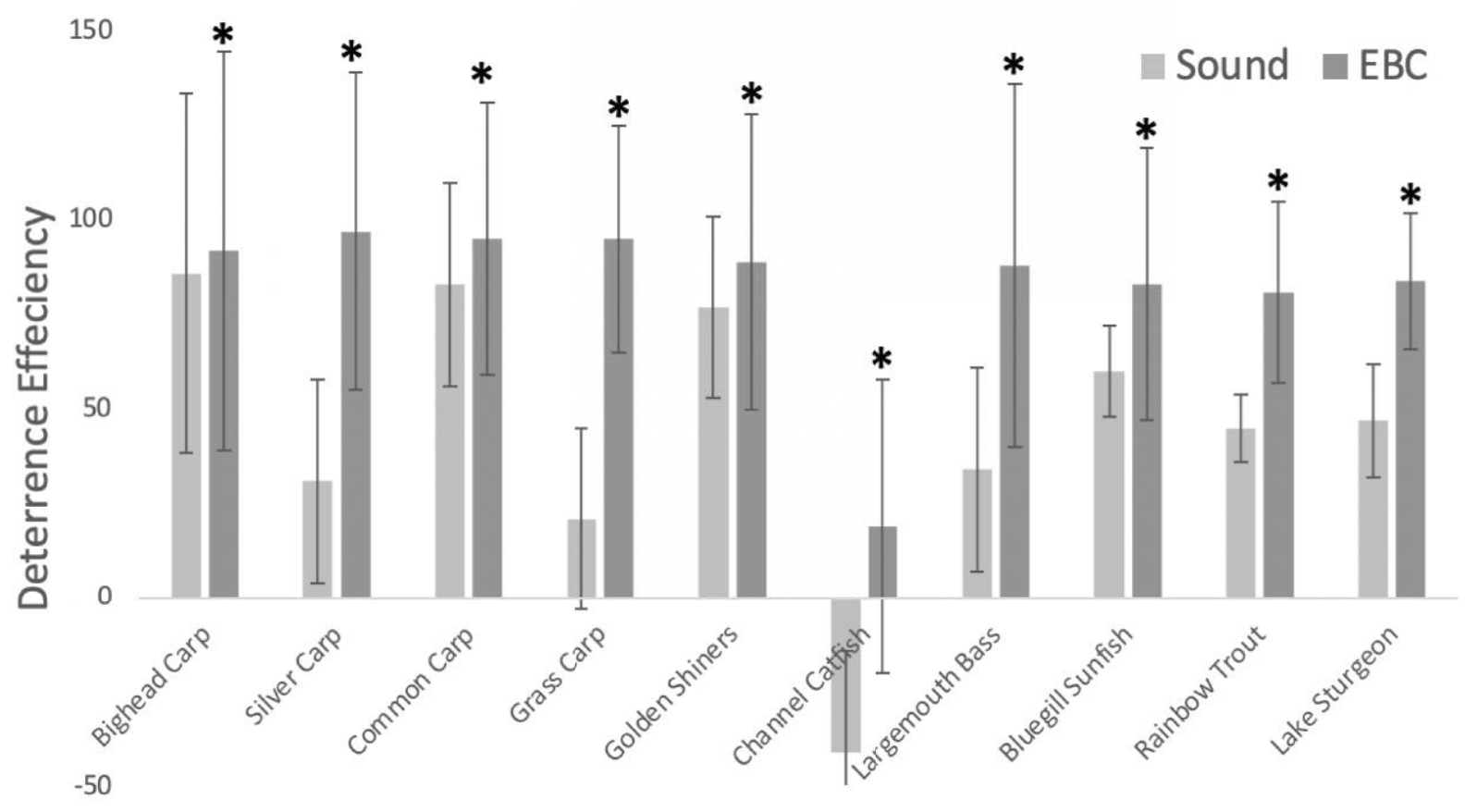




\section{Supplementary Files}

This is a list of supplementary files associated with this preprint. Click to download.

- FeelyandSorensenAugust82021Supplementaryinfo.pdf 